\title{
EN BUSCA DE INDICADORES PÚBLICOS DE RESULTADOS PARA EL CONTROL SOCIAL DEL PODER EN LOS MUNICIPIOS DEL ESTADO DE CAMPECHE
}

\author{
Seeking Public Outcome Indicators for Social Control of \\ Authorities in the Municipalities of the State of Campeche
}

Oscar López-Chan

Resumen: Con base en la aprobación de reformas a los artículos sexto y 134 de la Constitución General de México, se estableció la obligación de todos los órdenes de gobierno de difundir sus indicadores de gestión. En el caso de los gobiernos municipales, estos indicadores no suelen medir resultados concretos para la ciudadanía porque en las leyes no se define con claridad qué son o qué deben medir; son definidos por instancias externas — como los órganos de fiscalización —, o sólo miden procesos internos. En este sentido, se propone un conjunto de indicadores de resultados para los ayuntamientos a partir de sus competencias formales.

Palabras clave: rendición de cuentas, indicadores de resultados, municipios, transparencia, ciudadanos.

Abstract: With fundament in approved reforms at the articles 6th and 134 of the General Constitution of Mexico is a mandate for all government's orders to spread your management indicator. In the case of municipalities this indicators don't measure concretes outcomes for the citizens because aren't defined with precision in the laws what are, or what must to evaluate, are defined for extern instances as the oversight and control organisms, or measure intern process, only. In this way, is proposed a bundle of indicator for the municipalities with base in your formal competences.

Keywords: accountability, outcome indicator, municipalities, transparency, citizens.

Óscar López-Chan, doctor en Ciencias en Ecología y Desarrollo Sustentable por El Colegio de la Frontera Sur. Profesor-investigador de la Universidad Autónoma de Campeche. Temas de especialización: federalismo, desarrollo regional y municipios. Correo electrónico: oscarlopezchan@yahoo.com.mx.

Enviado a dictamen: 02 de noviembre de 2013. Aprobación: 25 de abril de 2013.

Revisiones: 1. 


\section{Introducción}

E n México, a raíz de la expedición de la Ley Federal de Transparencia y Acceso a la Información Pública en 2002, ${ }^{1}$ se inició un proceso de promulgación de leyes estatales en la materia que estableció la obligación de los gobiernos estatales y municipales de publicar información mínima de oficio, de libre acceso para la ciudadanía. Esta situación se fortaleció con la reforma al artículo sexto de la Constitución General ${ }^{2}$ para uniformar criterios de acceso y de publicidad de la información y donde se considera la obligatoriedad para todos los órdenes de gobierno de publicar indicadores de gestión.

Un problema de implementación es que dichos ordenamientos no establecen con claridad cuáles deben ser los contenidos específicos de los indicadores; por esta razón se requiere y se propone construir un conjunto mínimo de indicadores de resultados sobre materias de interés público en el ámbito municipal. Éstos deben permitir comparar resultados de gobiernos en condiciones institucionales similares en términos de eficacia y economía, relacionados con las obras y los servicios públicos a su cargo. Además, deben ser públicos para que la ciudadanía pueda conocer el grado de responsabilidad de su ayuntamiento, monitoree sus resultados y potencialmente representen una forma de control social — accountability vertical - ${ }^{3}$ sobre los poderes locales -más en casos donde sólo informan lo que les es conveniente- que permita hacer efectiva la rendición de cuentas hacia los ciudadanos. Además, este grupo de indicadores contribuiría a fortalecer el principio de máxima publicidad de la información gubernamental, a partir de su accesibilidad y utilidad pública, que evidencie el buen o mal desempeño de los ayuntamientos en los municipios.

\section{Rendición de cuentas como propósito público}

Cualquier sistema de gobierno que se precie de ser democrático necesita demostrar que ejerce el poder con legitimidad. No basta la legitimidad de origen a través de la elección popular. Tampoco es suficiente sustentarse en un conjunto de valores para configurar una legitimidad institucional. ${ }^{4}$ En todo momento debe garantizar los derechos fundamentales de los ciudadanos. Es decir, el ejercicio responsable del gobierno implica el cumplimiento de obligaciones como la de rendir cuentas a la ciudadanía debido a que no se ejerce el poder para fines privados, sino que el propósito es esencialmente público.

A la par de las obligaciones de los gobernantes están los derechos ciudadanos, como el de la libertad de expresión, cuyo contenido esencial, de acuerdo con la Declaración Universal de los Derechos Humanos de 1948, implica el "derecho de recibir, indagar y difundir información," el cual en la práctica se concreta en el derecho de acceso a la información pública. ${ }^{5}$ Éste fortalece la relación entre transparencia y democracia cuando el voto se ejerce en un contexto de conocimiento - de acceso a la información pública-, es decir, que la elección sólo puede darse entre alternativas viables cuando existe transparencia (Nieto, 2005).

En el mismo sentido, la relación entre democracia y rendición de cuentas opera cuando, al no estar afinados los mecanismos del gobierno como sistema, el último recurso del ciudadano para premiar o castigar al gobernante es el ejercicio del voto - si bien este esquema no funciona de manera perfecta cuando no existe reelección- ${ }^{6}$ No obstante, desde hace buen tiempo ha ganado consenso la idea de que los gobiernos se legitiman no sólo por la vía electoral o institucional, sino también por los rendimientos (Carrillo y Bañon, 1997). En este sentido, la rendición de cuentas entendida como la obligación de los gobernantes de informar y justificar sus actos y la capacidad de los ciudadanos de sancionarlos (Schedler, 2008) - se concreta cuando los gobiernos no sólo informan periódicamente a los ciudadanos o permiten el acceso a la información pública, sino también cuando sus acciones se transforman en resultados, tangibles y medibles, para la ciudadanía. 


\section{Indicadores de resultados en los municipios de México: estado de la cuestión}

La construcción de indicadores de resultados, si bien requiere de capacidades técnicas por parte de los gobiernos, es sobre todo un ejercicio de responsabilidad pública al comprometerse previamente un conjunto de resultados en el ejercicio de recursos públicos. Al mismo tiempo, estos indicadores representan una valiosa herramienta en términos de eficiencia y economía porque permiten comparar con sencillez las metas alcanzadas en relación con los recursos ejercidos. También permiten la comparación benchmarking - para evaluar los resultados del gobierno en turno en relación con gobiernos anteriores o de otras latitudes. Fundamentalmente son una herramienta de la ciudadanía para obtener información sobre el desempeño real de su gobierno para eventualmente premiarlo o exigirle mejores resultados. ${ }^{7}$

En términos estrictos, los indicadores de resultados no sólo tratan cuestiones de cantidad, como suele ocurrir en las comparaciones, sino también de responsabilidad y eficacia pública. Por ejemplo, afirmar que fueron pavimentados más metros de calles que en el gobierno anterior puede deberse a un mayor presupuesto circunstancial sin valorar el desempeño real a partir de costos y metas alcanzadas. Desde el punto de vista de los resultados, un mejor desempeño no significa plantearse metas modestas que siempre puedan cumplirse. Implica trazar y comparar metas con base en el presupuesto disponible, no sólo a partir de lo realizado en el ciclo anterior. Aunque es relativamente fácil ampliar metas disponiendo de un presupuesto suficiente o mayor, lo importante es mejorar la cantidad y la calidad de resultados con el mismo presupuesto o en un contexto de escasez.

De manera independiente a las bondades de un sistema de medición de resultados, en México ya es un imperativo legal la medición del desempeño gubernamental. En 2007, con base en la reforma al artículo 6to constitucional, se determinó la obligatoriedad de la Federación y de los estados de publicar a través de los medios electrónicos disponibles, la información completa y actualizada sobre sus indicadores de gestión y el ejercicio de los recursos públicos, aplicable también a municipios con población mayor a 70000 habitantes y a las demarcaciones territoriales del Distrito Federal. Adicionalmente, la reforma en 2008 del artículo 134 de la Constitución General estableció obligaciones adicionales para estados y municipios al quedar como sigue: ${ }^{8}$

Los recursos económicos de que dispongan la Federación, los estados, los municipios, el Distrito Federal y los órganos político-administrativos de sus demarcaciones territoriales, se administrarán con eficiencia, eficacia, economía, transparencia y honradez para satisfacer los objetivos a los que estén destinados.

Salvo lo relativo a honradez, es claro que la única manera de saber si los recursos se manejan con transparencia, eficiencia, eficacia y economía es a través de una valoración objetiva como pueden ser los indicadores de desempeño. Sobre este punto, la Ley Federal de Presupuesto y Responsabilidad Hacendaria, aprobada en 2006, introdujo el concepto de sistema de evaluación del desempeño obligatorio para la administración pública federal. En su reforma de $2007^{9}$ se establecieron los presupuestos con enfoque en resultados y la obligación de los estados y municipios (artículos 85 y 110) de presentar indicadores estratégicos y de gestión en caso de ejercicio de recursos federales o de gasto federalizado a través de una Matriz de Indicadores de Resultados (MIR).

\section{El caso del estado de Campeche}

En Campeche, la adecuación de la legislación local a los artículos 6to y 134 de la Constitución General, además de lo relativo a la medición del desempeño de la Ley Federal de Presupuesto y Responsabilidad Hacendaria - no obligatoria para todo el presupuesto de estados y municipios - fue a través de una reforma de la Ley Orgánica de los Municipios del Estado de Campeche (Congreso Campeche, 2011)..$^{10}$ Ésta contempló, entre 
otros contenidos, la obligación de los ayuntamientos de incluir en planes y programas municipales indicadores de gestión y medición del desempeño (sic) relativos a eficiencia, eficacia, economía, transparencia y honradez (art. 113, fracción VIII), y un apartado de indicadores de gestión y medición del desempeño en programas del presupuesto de egresos municipal (art. 144, fracción VII). Además estableció la obligación de expedir la reglamentación municipal de la materia (artículo 118 bis), la cual deberá contener indicadores de cobertura e impacto. ${ }^{11}$ Estos contenidos aplicarían para el año 2012; sin embargo, la revisión de leyes y presupuestos de los 11 municipios del estado de Campeche de ese ejercicio fiscal no incluye tales contenidos, por lo que hasta ahora no hay forma de verificar cómo los ayuntamientos están aplicando o construyendo sus indicadores. ${ }^{12}$

Se debe reconocer que desde 2002, con anterioridad a las reformas constitucionales y legales en los ámbitos nacional y estatal, la Auditoría Superior del Estado de Campeche (ASECAM, 2003) 13 $^{13}$ definió un sistema de indicadores de medición al desempeño gubernamental ${ }^{14}$ en conjunto con la Agencia de los Estados Unidos para el Desarrollo Internacional (United States Agency for International Development, USAID), y la Asociación Internacional de Administración de Ciudades y Condados (International City/Conty Management Asociation, ICMA), el cual es el único referente previo en el estado de Campeche para la definición de indicadores. Este sistema se aplicó por vez primera en la revisión y fiscalización de las cuentas públicas de 2011 del gobierno del estado y los municipios. Si bien desde un inicio el sistema planteó la medición de eficacia, eficiencia y economía, los indicadores se enfocaron hacia lo financiero, ${ }^{15}$ por lo cual muestran el estado de la hacienda pública municipal, más que resultados del ayuntamiento hacia la ciudadanía, precisamente porque el ámbito de aplicación del sistema es la cuenta pública municipal en su fiscalización por parte de la ASECAM. Pese a todo, ésta (ASECAM, 2003) definió un indicador muy interesante llamado costo de ejecución para medir la eficiencia y determinar así que los costos por unidad de obra "son acordes a los costos estándar por unidad de obra de la región." Sin embargo, éste todavía no se aplica. También para medir el desempeño administrativo definió un indicador de transparencia en relación con el ejercicio de recursos federales, cuyos componentes son los espacios de decisión conjunta con la sociedad, y la información y la atención a la ciudadanía. Esta propuesta de indicadores bien pudiera estar cercana a los indicadores de resultados, ya que tienen más relación con el desempeño esperado por la ciudadanía de parte de los gobiernos municipales.

El sistema de indicadores de medición del desempeño de la ASECAM representa el primer esfuerzo institucional en la entidad, y tal vez en México, para medir el desempeño de los ayuntamientos, ${ }^{16}$ iniciado antes de la obligación constitucional de los gobiernos de incluir indicadores de gestión y criterios de eficacia, eficiencia, economía, transparencia y honradez, establecidos en las reformas a los artículos sexto (2007) y 134 (2008) de la Constitución General, respectivamente. Pese a este mérito, se trata de una medición externa a los ayuntamientos, para efectos de la fiscalización de sus cuentas públicas, sin que estén obligados a realizar dicho ejercicio de manera interna, y mucho menos con involucramiento de la ciudadanía.

\section{Indicadores ¿de qué? Lo inasible del objeto}

Pese a diversas reformas a la Constitución General y a la de Campeche, ${ }^{17}$ a la Ley Federal de Presupuesto y Responsabilidad Hacendaria, y a las leyes Orgánica de los Municipios y del Poder Legislativo del Estado de Campeche (Congreso Campeche, 2009), ${ }^{18}$ el principal problema operacional es que ninguno de tales documentos define qué son los indicadores y qué deben medir; sólo establecen tipos que se usan indistintamente. Es decir, no existe consenso legislativo al respecto. Así, las constituciones y leyes se refieren a indicadores estratégicos, de gestión, de desempeño, de resultados, de cobertura y de impacto, sin que definan con precisión qué quiere decir cada uno o a qué hacen referencia (ver cuadro 1). Al revisar el espíritu de las leyes contenido en diversas iniciativas de reforma 
constitucional y legal, tampoco se encuentra una explicación al respecto ni se precisa qué se entiende por desempeño, gestión o resultados. Sólo en la iniciativa de reformas a la Ley Orgánica de la Administración Pública Federal se distingue entre indicadores estratégicos y de gestión al proponer que los primeros sean validados por la Secretaría de Hacienda y Crédito Público, y los segundos por la Secretaría de la Función Pública, incluyendo a ambos dentro de los indicadores de desempeño.

A partir de esta revisión, puede afirmarse que desde los ámbitos legislativos y de gobierno se fomenta una confusión entre los diferentes tipos de indicadores. Sin embargo, el principal déficit de claridad estriba en que no se distingue entre indicadores de procesos internos y los que miden resultados concretos para la ciudadanía en relación con la satisfacción de demandas o necesidades sociales. Por esta razón resulta conveniente hacer una distinción metodológica entre indicadores de gestión, referidos a procesos y desempeño internos, eindicadores de resultados, para medir el desempeño externo o para la ciudadanía. ${ }^{19}$ Estos últimos se diferencian claramente de los indicadores de gestión, que de manera genérica cualquier organización pública puede tener, pero que no identifican su quehacer principal. No obstante, ambos casos, en función de los criterios empleados para la medición, pueden catalogarse como indicadores de desempeño.

De acuerdo con Arriagada (2002, 23), "el desempeño está asociado con los logros individuales o colectivos al interior de una organización, y al alineamiento de la gestión con las metas y objetivos de la organización. Por lo tanto el desempeño es una magnitud de los logros de una organización.” En México, la Constitución General establece criterios para medir el desempeño: eficiencia, eficacia, economía, transparencia y honradez (artículo 134), y la obligación de todos los órdenes de gobierno de publicar sus indicadores de gestión (artículo sexto), lo cual se infiere que será a partir de tales criterios. Sin embargo, por un lado éstos no son suficientes para validar los resultados finales que se entregan a la sociedad y, por el otro, los gobiernos podrían concentrar su esfuerzo en indicadores de procesos internos para así cumplir con la legalidad sin que necesariamente eso se refleje en los resultados concretos que la ciudadanía espera de todo orden de gobierno.

\section{La construcción de indicadores de resultados}

De manera independiente a la falta de precisión sobre el tipo de indicadores y lo que deben medir, es ineludible que hasta la fecha la mayor parte de los entes públicos - poderes, estados, municipios, organismos autónomos - están obligados, constitucional y legalmente, a presentar de manera pública algún tipo de indicador. También es cierto que de acuerdo con el artículo 134 constitucional los criterios que deben emplear para ello son los de eficiencia, eficacia, economía, transparencia y honradez. Empero, la obligación de establecer indicadores de gestión se topa con la necesidad de construir indicadores que realmente sean útiles para medir el desempeño público de los gobiernos. Sin embargo, la mayor parte de los indicadores definidos por los entes gubernamentales apuntan más hacia la medición del desempeño interno en lo financiero o administrativo. En cierta manera se puede reconocer congruencia con el mandato del artículo sexto constitucional, que sólo menciona indicadores de gestión y no distingue entre desempeño interno o externo. Lo crítico del problema es que se construyen indicadores de gestión sin que necesariamente sean útiles para propósitos públicos.

Por las razones expuestas, se precisa de un tipo de indicador que señale si los ayuntamientos cumplen con sus competencias, facultades o misiones públicas, y además si son eficaces o eficientes. Por ello, resulta válido proponer indicadores de resultados, más que de gestión. Si los indicadores de resultados miden el desempeño externo, existe razón fundada para que también sean públicos, por lo cual tendrán la ventaja adicional de permitir la comparabilidad con municipios en similares condiciones institucionales. Cierto es que la definición de indicadores de resultados para que cumplan con su utilidad pública requiere que se basen en parámetros de comparación homogéneos (Iskandar, 2006). Al mismo tiempo, es necesario 
definir estándares municipales para cada indicador que permitan identificar ineficiencias, despilfarros o desvíos de recursos. Lo más importante del ejercicio es hacer públicos los estándares porque pueden constituir un instrumento valioso para que la ciudadanía pueda monitorear directamente el desempeño de su ayuntamiento. Esto será posible, obviamente, en un contexto de transparencia donde el propio municipio abra y difunda la información sobre los costos, metas y materiales de las obras y los servicios públicos.

No obstante, la evaluación del desempeño municipal a través de indicadores de resultados tiene puntos críticos. Puede exhibir las debilidades institucionales del ayuntamiento sometido a evaluación, aunque en realidad se trate de un problema estructural en la mayor parte de los ayuntamientos y no necesariamente de un rasgo particular del gobierno en cuestión. Esto puede generar un círculo vicioso: las resistencias a ser evaluado en el desempeño ${ }^{20}$ impiden la mejora de la gestión por falta de información -indicadores - derivada de una evaluación objetiva, lo cual a su vez empeora el problema inicial.

La medición de desempeño no es un sistema policial de control del funcionario municipal en el cumplimiento de sus tareas, sino un sistema que permite saber con precisión cuál es la capacidad real de la organización para cumplir sus metas, en atención a la disponibilidad real de los medios y recursos, y al conocimiento, experiencia, esfuerzo, capacidad y motivación de su equipo humano (Arriagada, 2002: 56). Y como tal debe entenderse.

\section{Indicadores públicos de resultados para el control social del poder en los municipios}

La responsabilidad política implica la capacidad de poder remover al gobernante en caso de fallas (Crespo, 2001). Sin embargo, en México, en la práctica, la única forma viable con que cuenta el ciudadano para remover, sancionar o castigar al gobernante es mediante el voto en elecciones periódicas. Pero este medio es limitado ya que no tiene el atributo de remover al gobernante en ejercicio; sólo de elegirlo, pues se ha rechazado reiteradamente la posibilidad de establecer por la vía legislativa la figura de revocación del mandato o de otros mecanismos de consulta y participación social como el referéndum y el plebiscito. ${ }^{21}$ Cierto es que la transparencia y el acceso a la información pública en México han puesto los cimientos para una cultura de rendición de cuentas, pero todavía resulta incompleta en tanto no existan claros mecanismos para sancionar a los gobernantes que incumplen con estos mandatos y el de un ejercicio responsable del poder. A la par, el establecimiento de obligaciones legales para que los decisores informen acerca de su desempeño público a través de indicadores, resulta también limitado porque son éstos, y no los ciudadanos, los que definen lo que se habrá de medir, evaluar e informar. Al mismo tiempo — como ya se argumentó-, la ambigüedad de las leyes, al no establecer claramente las distinciones entre gestión y resultados, ha ocasionado que la mayor parte de los indicadores definidos en realidad midan procesos internos y no resultados concretos para la ciudadanía. Se ha construido todo un andamiaje institucional para la definición y publicación de indicadores, que dicen poco a la ciudadanía, y que tal vez contribuyan menos a una toma de decisiones enfocada a la resolución efectiva de los problemas públicos. ${ }^{22}$

Paralelamente, no todo el universo de recursos ejercido por los municipios llega a ser revisado y fiscalizado por los órganos correspondientes. Pese a la profesionalización y al mejoramiento de las técnicas de auditoría por parte del órgano de fiscalización, en el estado de Campeche alrededor del 15\% de los recursos ejercidos por los municipios no se fiscaliza, pues en los años 2009, 2010 y 2011 se fiscalizaron el 82.2\%, el 86.3\% y el $84.6 \%$, respectivamente (ver tabla 1). Por esta razón, se requiere incrementar los controles sociales sobre dicho ejercicio, pero a través de medios accesibles, visibles y útiles a los ciudadanos. Por ejemplo, al ciudadano no le interesa si el ayuntamiento tiene liquidez o cuál es su resultado operacional financiero, entre otros indicadores determinados por la Auditoría Superior del Estado de Campeche para un año específico, sino que la calle o la red de agua potable construida en su colonia se ejecutó a un precio y calidad adecuados. 
No obstante, sobre la base del acceso a la información pública es posible avanzar hacia un conjunto de indicadores públicos que se enfoque fundamentalmente a resultados, en términos de efectividad - resolución de los problemas públicos-, eficiencia —al menor costo posible - y responsabilidad — ejercicio honesto y responsable de los recursos públicos-. Se trata de construir indicadores con base en las competencias municipales y la información que los ayuntamientos generan - por transparencia o acceso a la informaciónmediante el cual los ciudadanos puedan monitorear y valorar sus resultados, y en función de los resultados, al menos, pueda haber un reconocimiento o sanción públicos. ${ }^{23}$

\section{Propuesta de indicadores de resultados en los municipios}

El diseño de indicadores de desempeño sobre la gestión o los procesos (Arriagada, 2002) es una tarea que corresponde al ayuntamiento. Sin embargo, en términos de la rendición de cuentas, es más provechoso trabajar en un conjunto de indicadores de resultados que sean útiles a los ciudadanos. Es decir, indicadores que trabajen más desde la perspectiva del ciudadano que del gobierno municipal.

A partir de la coincidencia en la observación de que todo sistema de medición del desempeño debe ser consistente o congruente con las competencias o misión municipales (Arriagada, 2002; Iskandar, 2006), se busca que los indicadores por definir muestren cómo el ayuntamiento genera resultados para la ciudadanía en sus áreas competenciales. En México, éstas son las funciones y servicios públicos municipales: agua, drenaje, alumbrado público, recogida de basura y calles. Sin embargo, una dificultad para definir indicadores sobre una base común es la heterogeneidad municipal manifestada también en la forma como presentan la información.

Independientemente de la transparencia, del acceso a la información y del mandato constitucional para los municipios de presentar indicadores de gestión, hasta ahora no existe fundamento legal para presentarlos sobre una base común que permita al ciudadano monitorear a su gobierno o comparar sus resultados con otros. En el caso de la fiscalización sobre los municipios en México, pese a las técnicas estándar empleadas por los organismos responsables no se ha desarrollado la homogeneización en las auditorías de desempeño y programáticas presupuestales, como sugiere Nieto (2005: 138). En el mediano plazo, la única posibilidad de que esto ocurra dependerá de la manera como se apliquen las reformas a la Ley General de Contabilidad Gubernamental aprobadas en 2012, ${ }^{24}$ a partir de las cuales se espera que el ejercicio del gasto de estados y municipios sea más transparente en lo relativo a la información financiera y presupuestal. Aunque habrá un mayor cúmulo de información disponible para el ciudadano, no existe garantía de que ésta se refiera a lo que realmente le interesa, como la solución de los problemas de su entorno inmediato, si bien lo positivo es la obligación para todos los órdenes de gobierno de presentar la información en forma homogénea, lo cual permitirá la comparación.

Independientemente de la voluntad de los gobiernos, de la capacidad de los órganos de fiscalización o del mandato de leyes ad hoc para construir y difundir indicadores que realmente interesen a la ciudadanía, existen indicadores que pueden mostrar la responsabilidad de los ayuntamientos en relación con su contexto social, como los salarios de sus integrante ${ }^{25} \mathrm{y}$ con los costos de las principales obras y de los servicios públicos - la construcción de calles y el suministro de agua potable, por ejemplo-. Aquí la premisa es construirlos y difundirlos para que la propia ciudadanía pueda calcularlos o monitorearlos.

Partiendo de las principales competencias constitucionales de los ayuntamientos en México que afectan o inciden sobre el entorno inmediato del ciudadano o le son más visibles, y con el afán de facilitar la comparación de resultados entre municipios, en el cuadro 2 se propone un conjunto de indicadores que contribuyan al propósito de mostrar resultados concretos a la ciudadanía. Las fuentes de consulta para su elaboración son los informes municipales 
de gobierno, datos obtenidos a través de solicitudes de transparencia y documentos técnicos sobre cada temática. Un punto fundamental para conocer la responsabilidad en el ejercicio de los recursos públicos de los gobiernos municipales es la comparación de costos, pues el análisis conjunto de los indicadores propuestos puede dar indicios al ciudadano acerca de la eficiencia y la honestidad en el ejercicio de los recursos públicos en su municipio.

Es probable que para un mismo tipo de obra pueda haber cierto grado de variación debido a la concentración-dispersión de la población, a problemas de accesibilidad, a la geografía o accidentes geográficos, o al tipo de suelo. No obstante, para un mismo tipo de obra o servicios - como los descritos en el cuadro 2-, relacionados con las condiciones señaladas, se supone que debe haber un costo promedio similar. Aquí el dato clave es el costo por unidad de obra, el cual puede ser el elemento clave para evaluar la eficacia, la eficiencia y, en un análisis más fino, la calidad. Como destaca Bonnefoy y Armijo,

[...] los indicadores de insumos (inputs) o productos (outputs) por sí solos no tienen valor informativo para la toma de decisiones, necesitamos saber el costo por unidad producida (eficiencia, costo medio), la oportunidad de esa producción (calidad), y si los recursos financieros están correctamente ejecutados (economía) (Bonnefoy y Armijo, 2005: 50).

Estos elementos pueden enriquecerse en la medida en que son públicos los procesos de contratación de obras y servicios, pues permitirán al ciudadano obtener información sobre las decisiones de los gobiernos municipales sin necesidad de buscar en los informes de gobierno o tener que solicitar la información por la vía de la transparencia. Este tipo de medios puede ser una herramienta útil para los ciudadanos porque en la fiscalización de las cuentas públicas de los ayuntamientos los órganos fiscalizadores no necesariamente generan información que realmente interese a los ciudadanos, como el costo y calidad de las obras -más en un ánimo de comparación-, o en ocasiones los datos técnicos suministrados poco le dicen a la ciudadanía sobre la responsabilidad en el ejercicio de recursos, para concretar, la rendición de cuentas.

\section{Conclusiones}

El empleo de indicadores de desempeño en las organizaciones públicas, en general, no debe verse como un fin en sí mismo. Particularmente, en los gobiernos municipales la medición de procesos internos tampoco debe tenerse como una meta por lograr a toda costa. Cierto es que toda organización se mide por sus resultados, pero de manera fundamental por aquéllos que se refieren a los usuarios finales de los bienes y servicios producidos por la misma. Desafortunadamente, este tipo de prácticas no son generalizadas entre los ayuntamientos, ya por falta de voluntad política, ya por ausencia de capacidades técnicas o, sobre todo, por la falta de un marco legal o reglamentario preciso y claro para su implementación. Hasta ahora, en la generalidad de los municipios se aprecia que este tipo de iniciativas se implanta por determinación externa. No son parte de la cultura organizacional hasta que una ley así lo determina. Eso es desafortunado. Sin embargo, también lo es que los primeros intentos derivados de las obligaciones legales se traduzcan en ejercicios técnicos que, en términos de responsabilidades políticas y sociales, poco dicen a la población. Es decir, los indicadores que se crean sirven eventualmente a los usuarios internos, pero no a los ciudadanos.

Por las razones planteadas, hace falta construir indicadores que se refieran puntualmente a los resultados del ejercicio de las competencias de los ayuntamientos que a la vista de los ciudadanos efectivamente contribuyen a mejorar las condiciones de vida de su comunidad. Ése es el reto fundamental. En ese sentido, puede resultar útil impulsar desde la sociedad y la academia la integración de indicadores públicos de resultados para que, en un ejercicio de responsabilidad, los gobiernos municipales se vean obligados a rendir cuentas a los ciudadanos. Los indicadores de resultados sólo serán la medición de lo que la ciudadanía percibe de 
manera directa. Al fin y al cabo la realidad no se cambia con indicadores.

\section{Agradecimientos}

El autor agradece el financiamiento del Programa de Mejoramiento del Profesorado (PROMEP) para el desarrollo del proyecto "Medición y evaluación del desempeño para la transparencia y la rendición de cuentas en municipios del estado de Campeche 20012010", a las licenciadas Sara Mejía y Mayra Aguayo por su gentil atención para la liberación oportuna de recursos para el proyecto, a la Br. Valeria Gorián por su apoyo en la recopilación documental y, fundamentalmente, a mi alma mater, la Universidad Autónoma de Campeche, por el cobijo académico.

\section{Notas}

${ }^{1}$ Publicada en el Diario Oficial de la Federación el 11 de junio de 2002.

${ }^{2}$ Publicada en el Diario Oficial de la Federación el 20 de julio de 2007. Se adiciona un párrafo con siete fracciones al artículo sexto constitucional.

${ }^{3}$ El término fue acuñado por O’Donnell (2004) y se refiere a la capacidad de los ciudadanos para establecer controles sobre las agencias del Estado, principalmente a través de las vías electoral y societal para vigilar y sancionar a las autoridades políticas.

${ }^{4}$ Término propuesto por Carrillo y Bañon (1997).

${ }^{5}$ Entre los derechos a una gestión pública democrática figuran "instituciones de gobierno transparentes y responsables" (Resolución 1999/57 de la Comisión de Derechos Humanos de las Naciones Unidas).

${ }^{6}$ Para efectos de rendición de cuentas, toda reelección debiera tener su contraparte en la revocación de mandato.

${ }^{7}$ Autores como O’Donnell (2004) y Schedler (2008) reconocenqueenlasdemocraciasprácticamenteelúnico instrumento para premiar o castigar a los gobernantes es mediante el voto; de ahí la necesidad de desarrollar instrumentos permanentes, como indicadores públicos de resultados, que no estén sujetos sólo a periodos de tiempo determinados, como las elecciones.
${ }^{8}$ Publicada en el Diario Oficial de la Federación el 7 de mayo de 2008, mediante la adición de un segundo párrafo al artículo 134 constitucional. Debe anotarse que desde 1982, con la primera reforma al mismo artículo, se incluyeron los criterios de eficacia, eficiencia y honradez, pero sólo eran aplicables al gobierno federal y al del Distrito Federal — publicada en el Diario Oficial de la Federación el 28 de diciembre de 1982-.

${ }^{9}$ Reforma publicada en el Diario Oficial de la Federación el 1 de octubre de 2007. Incluyó nueva denominación al capítulo III de la citada Ley para quedar como "De la transparencia e información sobre el ejercicio del gasto federalizado."

${ }^{10}$ Presentada el 20 de julio de 2010 por la diputada Ana Martha Escalante Castillo, dictaminada el 17 de mayo de 2011, aprobada mediante decreto núm. 169 el 6 de octubre de 2011, y publicada en el Periódico Oficial del Estado de Campeche el 27 de octubre de 2011.

${ }{ }^{11}$ Esta obligación, de acuerdo con el artículo segundo transitorio del Decreto de Reforma, venció el 9 de febrero de 201l, pero hasta la fecha no existe evidencia de que alguno de los ayuntamientos del estado de Campeche haya expedido el reglamento correspondiente.

${ }^{12}$ Para 2012 tal obligatoriedad no aplica para los planes municipales de desarrollo ya que, de acuerdo con la Ley Orgánica de los Municipios, éstos se presentan a los cuatros meses de inicio de cada gobierno municipal. En Campeche los nuevos ayuntamientos tomaron posesión el 1 de octubre de 2012, por lo cual la fecha de presentación del plan vence el 31 de enero de 2013.

${ }^{13}$ Es el órgano de fiscalización del estado y dependiente del congreso local.

${ }^{14}$ Instrumento técnico para evaluar, analizar y medir el desempeño de los gobiernos estatal y municipal, en el marco de la revisión y fiscalización de la cuenta pública para comparar los resultados alcanzados en diversos ejercicios gubernamentales (ASECAM, 2003).

${ }^{15}$ Salvo los indicadores relativos a servicios públicos relleno sanitario y rastro público-, que se enfocan a verificar el cumplimiento de normas oficiales mexicanas sobre la materia y de la Ley de Salud del Estado de Campeche. 
${ }^{16}$ Esta experiencia de innovación en la fiscalización que implementó un sistema de medición del desempeño obtuvo en 2003 el Reconocimiento Especial al Fortalecimiento Municipal del Premio Gobierno y Gestión Local, otorgado por el Centro de Investigación y Docencia Económicas (CIDE) y la Fundación Ford (Mixcóatl, 2004).

${ }_{17}$ Publicada en el Periódico Oficial del Estado de Campeche el 18 de noviembre de 2009, mediante Decreto núm. 3, que reformó el artículo 105, fracción III, inciso e, para establecer la obligación de los municipios de administrar sus recursos con los criterios de eficiencia, eficacia, economía, transparencia y honradez.

${ }^{18}$ Donde se establecen como objeto de la fiscalización y como atribuciones de la Auditoría Superior del Estado la evaluación del cumplimiento de objetivos y metas contenidos en los programas, y del desempeño de indicadores de eficiencia, eficacia y economía, aprobados en el presupuesto (artículos 133, fracción III, y 135, fracción IV). Decreto publicado el 10 de junio de 2009 en el Periódico Oficial del Estado de Campeche.

19 Arriagada (2002) distingue entre la medición de desempeño que se interesa en resultados y la medición de desempeño que se interesa en procesos.

${ }^{20}$ Como se demuestra en Iskandar (2006) para el caso del municipio de Guadalajara en el establecimiento del SINDES (Sistema de Indicadores de Desempeño).

${ }^{21}$ Como es el caso de la reforma política aprobada el 19 de abril de 2012 por la Cámara de Diputados, que desechó tales propuestas de la iniciativa original (CNN México, 2012).

${ }^{22}$ Por ejemplo, en seguridad pública se puede encontrar toda una batería de indicadores donde lo único claro es el incremento sustancial del presupuesto en la materia, pero en cuanto a resultados todavía representa un pasivo que, lejos de reducirse, se incrementa.

${ }^{23}$ Una experiencia similar y previa, pero en materia de transparencia, es desarrollada por Ciudadanos por Municipios Transparentes (www.cimtra.org.mx) para establecer un sistema de medición de la misma en municipios a través de un cuestionario de 31 preguntas. La particularidad es que sólo se lleva a cabo en aquellos municipios que consienten someterse a tal evaluación.
${ }^{24}$ Esto dependerá de los formatos que se definan por parte del Consejo Nacional para la Armonización Contable (CONAC), para la presentación de la información y de la desagregación que finalmente se apruebe; por ejemplo, puede incluir información relativa al costo y los beneficiarios de una obra en una comunidad determinada, pero no necesariamente incluir especificaciones técnicas sobre la calidad de la obra o precios unitarios de los insumos.

${ }^{25}$ Aun así, hay casos donde la información no se presenta de manera clara; es necesario hacer alguna operación aritmética para obtener el dato final o, definitivamente no se presenta pese al mandato legal.

\section{Bibliografía}

Arriagada, Ricardo (2002), Diseño de un sistema de medición del desempeño para evaluar la gestión municipal: una propuesta metodológica, Santiago de Chile: Instituto Latinoamericano de Planificación Económica y Social. Auditoría Superior del Estado de Campeche (ASECAM) (2003), Sistema de indicadores de medición del desempeño gubernamental. México: Poder Legislativo del Estado de Campeche/Auditoría Superior del Estado de Campeche/ International City Manager Asociation/USAID.

Auditoría Superior del Estado de Campeche (ASECAM) (2011), Informes de resultados de la revisión y fiscalización de las cuentas públicas del estado de Campeche 2009-2011, México: Poder Legislativo del Estado de Campeche/ Auditoría Superior del Estado de Campeche.

Bonnefoy, Juan y Marianela Armijo (2005), Indicadores de desempeño en el sector público, Santiago de Chile: Instituto Latinoamericano y del Caribe de Planificación Económica y Social/CEPAL.

Carrillo, Ernesto y Rafael Bañon (1997), "La legitimidad de la Administración Pública”, en Ernesto Carrillo y Rafael Bañon (comps.), La nueva Administración Pública," Madrid: Alianza Universidad.

CNN México (2012), "La Cámara de Diputados aprueba una reforma política recortada", en CNN México, 20 de abril, 〈http://mexico.cnn.com/nacional/2012/04/19/lacamara-de-diputados-aprueba-una-reforma-politicarecortada> [2 de marzo de 2013]. 
Crespo, José Antonio (2001), Fundamentos políticos de la rendición de cuentas, México: Auditoría Superior de la Federación.

Iskandar, Antonio (coord.) (2006), Estudio comparado sobre sistemas de medición de desempeño municipal en América Latina, s.l.:International City/County Management Association (ICMA)/Oficina Regional de Desarrollo Sostenible del Buró para América Latina y el Caribe-USAID.

Mixcóatl, Gerardo (2004), "Innovaciones en la fiscalización en el estado de Campeche", en Rodolfo García del Castillo (coord.), Gestión local creativa: experiencias innovadoras en México. Premio Gobierno y Gestión Local, México: CIDE.
Nieto Castillo, Santiago (2005), "Rendición de cuentas y transparencia en los gobiernos locales," en Máximo Gámiz Parral y José Rivera Rodríguez (coords.), Las aportaciones de las entidades federativas a la reforma del Estado, México: UNAM-Instituto de Investigaciones Jurídicas, pp. 121-157.

O’Donnell, Guillermo (2004), “Accountability horizontal: la institucionalización legal de la desconfianza política”, en Revista Española de Ciencia Política, núm. 11, octubre, pp. 11-31.

Schedler, Andreas (2008), ¿Qué es la rendición de cuentas?, México: Instituto Federal de Acceso a la Información Pública. 


\begin{tabular}{|c|c|c|c|c|c|c|c|c|}
\hline 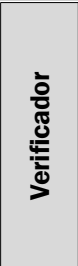 & 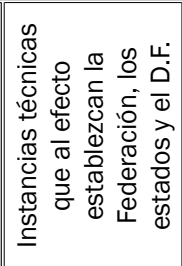 & 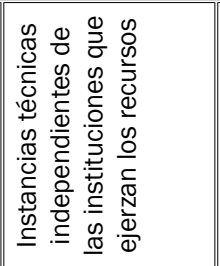 & 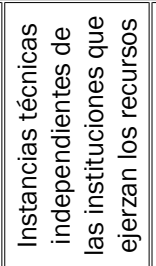 & 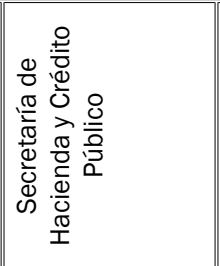 & 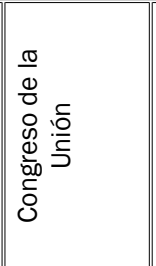 & $\frac{\frac{\circ}{0}}{\frac{0}{\overline{0}}}$ & 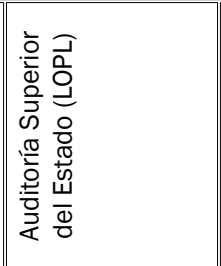 & 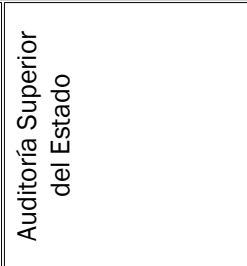 \\
\hline 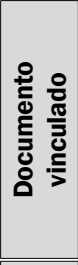 & & & & 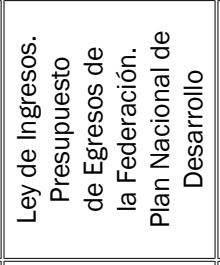 & 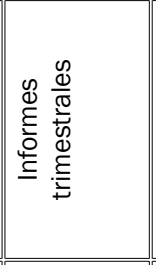 & 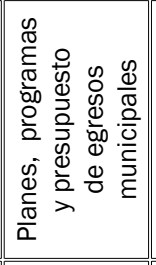 & 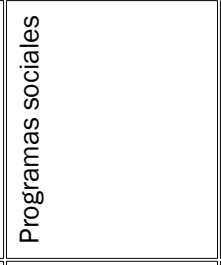 & 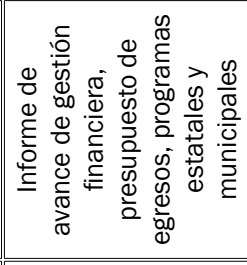 \\
\hline $\begin{array}{l}\frac{\pi}{0} \\
\frac{0}{0} \\
\frac{0}{\pi} \\
\frac{0}{\alpha}\end{array}$ & 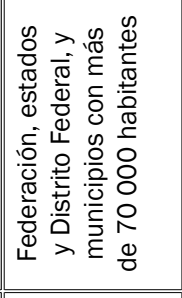 & 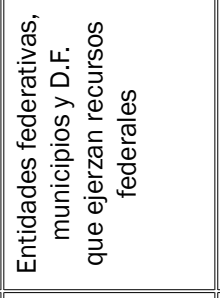 & 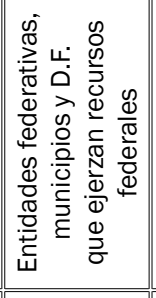 & 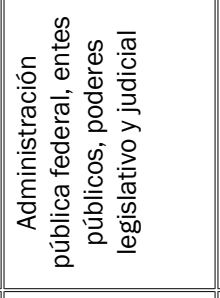 & 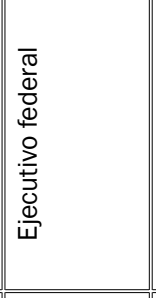 & 总 & 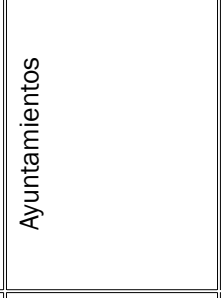 & 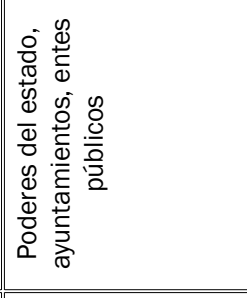 \\
\hline 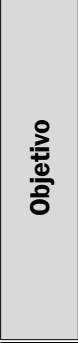 & $\begin{array}{l}0 \\
\frac{0}{0} \\
\frac{0}{x} \\
0 \\
2 \\
z\end{array}$ & 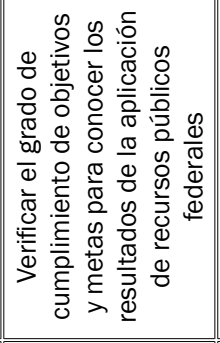 & 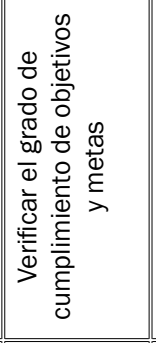 & 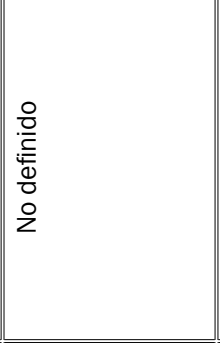 & 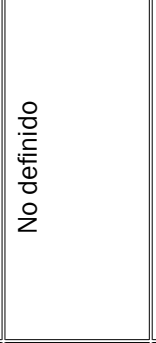 & $\begin{array}{l}\frac{0}{0} \\
\frac{.0}{10} \\
\frac{10}{0} \\
\frac{1}{2} \\
\frac{1}{2}\end{array}$ & 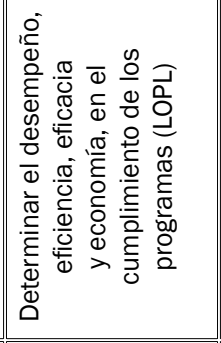 & 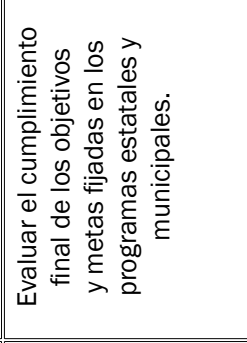 \\
\hline$\frac{\check{0}}{\frac{0}{0}}$ & $\begin{array}{l}0 \\
\frac{0}{0} \\
\frac{0}{x} \\
0 \\
2 \\
z\end{array}$ & $\begin{array}{l}0 \\
\frac{0}{0} \\
\frac{w}{x} \\
0 \\
0 \\
z\end{array}$ & 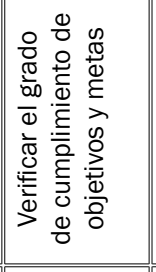 & 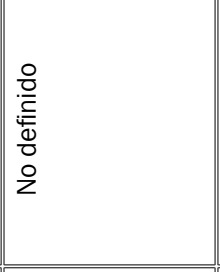 & 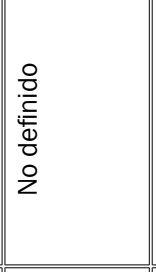 & $\begin{array}{l}\frac{0}{2} \\
\frac{0}{E} \\
\frac{1}{0} \\
\frac{10}{0} \\
0 \\
2\end{array}$ & 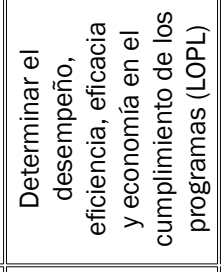 & 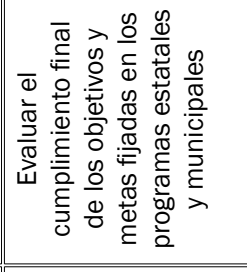 \\
\hline 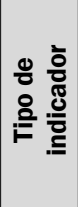 & $\begin{array}{l}c \\
: 0 \\
\bar{y} \\
0 \\
0.0 \\
0 \\
0 \\
0\end{array}$ & 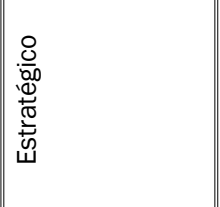 & 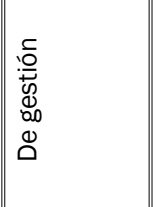 & 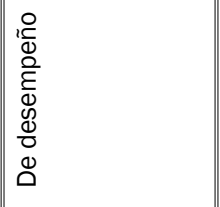 & 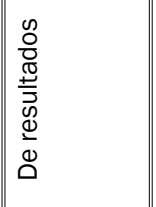 & 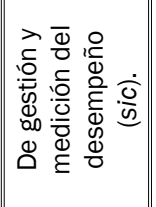 & 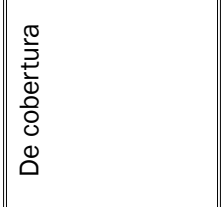 & 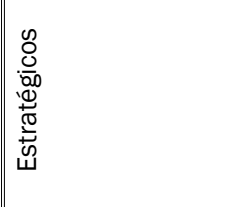 \\
\hline 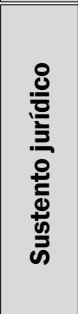 & 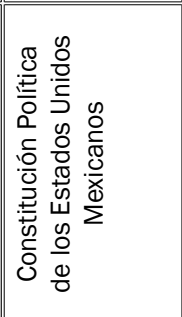 & 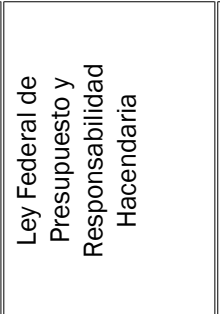 & 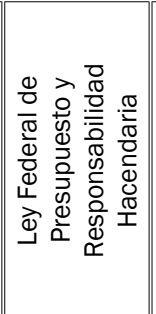 & 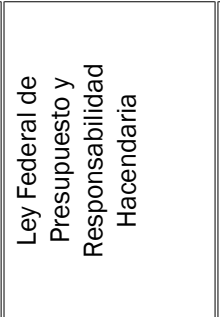 & 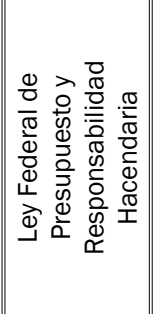 & 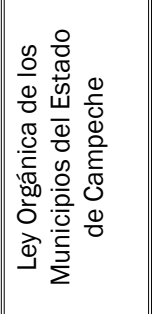 & 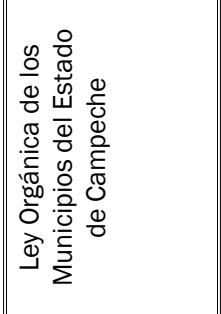 & 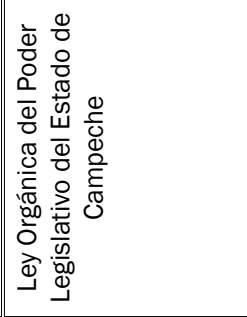 \\
\hline
\end{tabular}


Cuadro 2. Indicadores para monitorear las responsabilidades de los ayuntamientos en el ejercicio de sus competencias

\begin{tabular}{|c|c|c|c|c|c|c|}
\hline Competencia & Obra o servicio & $\begin{array}{r}\text { Insumo o } \\
\text { material }\end{array}$ & Unidad de medida & Costo por unidad & $\begin{array}{l}\text { Promedio } \\
\text { municipal }\end{array}$ & $\begin{array}{l}\text { Otra unidad de } \\
\text { medida }\end{array}$ \\
\hline \multirow[b]{2}{*}{ Agua potable } & $\begin{array}{l}\text { Red de agua } \\
\text { potable }\end{array}$ & $\begin{array}{l}\text { Tubería de PVC } \\
\text { Acero }\end{array}$ & Metro lineal & $\begin{array}{l}\text { Costo total } \\
\text { de obra/ } \\
\text { metros lineales } \\
\text { construidos }\end{array}$ & $\begin{array}{l}\text { Sumatoria de } \\
\text { costo total de } \\
\text { obras/ML }\end{array}$ & $\begin{array}{l}\text { Pulgadas de } \\
\text { diámetro }\end{array}$ \\
\hline & Planta de bombeo & & $\begin{array}{l}\text { Gasto (metros } \\
\text { cúbicos/segundo) }\end{array}$ & $\begin{array}{l}\text { Costo total de } \\
\text { obra/gasto por } \\
\text { segundo }\end{array}$ & $\begin{array}{l}\text { Sumatoria } \\
\text { de costos } \\
\text { por unidad/ } \\
\text { número de } \\
\text { plantas }\end{array}$ & $\begin{array}{l}\text { Costo por } \\
\text { consumo } \\
\text { de energía } \\
\text { eléctrica/gasto }\end{array}$ \\
\hline $\begin{array}{l}\text { Tratamiento } \\
\text { de aguas } \\
\text { residuales }\end{array}$ & $\begin{array}{l}\text { Planta de } \\
\text { tratamiento }\end{array}$ & & $\begin{array}{l}\text { Metros cúbicos } \\
\text { tratados }\end{array}$ & $\begin{array}{l}\text { Costo total de } \\
\text { planta/metros } \\
\text { cúbicos tratados }\end{array}$ & $\begin{array}{l}\text { Sumatoria } \\
\text { de costos } \\
\text { por unidad } \\
\text { de plantas/ } \\
\text { número de } \\
\text { plantas }\end{array}$ & $\begin{array}{l}\text { Vida útil de la } \\
\text { planta }\end{array}$ \\
\hline \multirow{2}{*}{$\begin{array}{l}\text { Alumbrado } \\
\text { público }\end{array}$} & $\begin{array}{l}\text { Alumbrado } \\
\text { público }\end{array}$ & $\begin{array}{l}\text { Incandescente, } \\
\text { halógena, } \\
\text { mercurial led, } \\
\text { vapor de sodio, } \\
\text { etcétera. }\end{array}$ & Luminarias & Precio por unidad & $\begin{array}{l}\text { Costo total de } \\
\text { luminarias/ } \\
\text { total de } \\
\text { luminarias }\end{array}$ & $\begin{array}{l}\text { Horas de vida } \\
\text { de luminaria }\end{array}$ \\
\hline & & $\begin{array}{l}\text { Consumo de } \\
\text { energía }\end{array}$ & kilowatio/hora & $\begin{array}{l}\text { Precio por } \\
\text { kilowatio/hora }\end{array}$ & $\begin{array}{l}\text { Costo total de } \\
\text { alumbrado } \\
\text { público/ } \\
\text { luminarias en } \\
\text { el municipio }\end{array}$ & $\begin{array}{l}\text { Precio por } \\
\text { unidad/horas } \\
\text { de vida útil }\end{array}$ \\
\hline \multirow{2}{*}{$\begin{array}{l}\text { Recolección, } \\
\text { traslado, } \\
\text { tratamiento } \\
\text { y disposición } \\
\text { final de } \\
\text { residuos }\end{array}$} & $\begin{array}{l}\text { Recolección de } \\
\text { basura }\end{array}$ & $\begin{array}{l}\text { Tipo de vehículo } \\
\text { recolectores }\end{array}$ & $\begin{array}{l}\text { Tonelada de } \\
\text { basura }\end{array}$ & $\begin{array}{l}\text { Gasto de } \\
\text { operación por } \\
\text { recolección/ } \\
\text { tonelada } \\
\text { recolectadas }\end{array}$ & $\begin{array}{l}\text { Sumatoria } \\
\text { de precios } \\
\text { por tonelada } \\
\text { movilizada/ } \\
\text { número de } \\
\text { municipios } \\
\end{array}$ & $\begin{array}{l}\text { Distancia } \\
\text { de traslado, } \\
\text { eficiencia } \\
\text { energética } \\
\text { de vehículos } \\
\text { recolectores }\end{array}$ \\
\hline & $\begin{array}{l}\text { Tratamiento o } \\
\text { disposición de } \\
\text { basura }\end{array}$ & Relleno sanitario & $\begin{array}{l}\text { Tonelada de } \\
\text { basura }\end{array}$ & $\begin{array}{l}\text { Gasto de } \\
\text { operación por } \\
\text { tratamiento/ } \\
\text { toneladas tratadas }\end{array}$ & $\begin{array}{l}\text { Sumatoria } \\
\text { de precios } \\
\text { por tonelada } \\
\text { tratada/ } \\
\text { número de } \\
\text { municipios }\end{array}$ & $\begin{array}{l}\text { Ingresos por } \\
\text { reciclaje de } \\
\text { residuos } \\
\text { Cumplimiento } \\
\text { de normas }\end{array}$ \\
\hline Calles & $\begin{array}{l}\text { Pavimentación, } \\
\text { repavimentación, } \\
\text { bacheo }\end{array}$ & $\begin{array}{l}\text { Asfalto, concreto } \\
\text { hidráulico }\end{array}$ & Metro cuadrado & $\begin{array}{l}\text { Costo total de } \\
\text { obra/metros } \\
\text { cuadrados } \\
\text { construidos o } \\
\text { reparados }\end{array}$ & $\begin{array}{l}\text { Sumatoria de } \\
\text { precios por } \\
\text { obra /obras a } \\
\text { comparar }\end{array}$ & $\begin{array}{l}\text { Grosor de } \\
\text { pavimento, } \\
\text { vida útil }\end{array}$ \\
\hline
\end{tabular}

Fuente: elaboración propia con base en la legislación aportada e informes de gobiernos municipales. 
Tabla 1. Recursos fiscalizados por la Auditoría Superior del Estado a municipios de Campeche 2009-2011 - pesos a precios corrientes - en el ejercicio de sus competencias

\begin{tabular}{|c|c|c|c|c|c|c|c|c|c|}
\hline Año & & 2009 & & & 2010 & & & 2011 & \\
\hline Municipio & Egresos & Auditado & $\%$ & Egresos & Auditado & $\%$ & Egresos & Auditado & $\%$ \\
\hline Calakmul & 115155888 & 110483310 & 95.9 & 133630177 & 124554391 & 93.2 & 153098871 & 122825632 & 80.2 \\
\hline Calkiní & 167852535 & 164230235 & 97.8 & 190453810 & 187591534 & 98.5 & 192263744 & 171585351 & 89.2 \\
\hline Campeche & 920544741 & 662315493 & 71.9 & 1066530274 & 820265057 & 76.9 & 1070809543 & 840982612 & 78.5 \\
\hline Candelaria & 150438508 & 143782991 & 95.6 & 201006342 & 170348763 & 84.7 & 205223947 & 201906912 & 98.4 \\
\hline Carmen & 1039411170 & 844144628 & 81.2 & 1068185005 & 972714480 & 91.1 & 1161669381 & 967457450 & 83.3 \\
\hline Champotón & 311124941 & 249428652 & 80.1 & 421622065 & 338875055 & 80.4 & 379438041 & 326688457 & 86.1 \\
\hline Escárcega & 215672413 & 181184327 & 84.0 & 225861656 & 195493416 & 86.5 & 245220447 & 203029772 & 82.8 \\
\hline Hecelchakán & 111947192 & 105052480 & 93.8 & 124119262 & 120665943 & 97.2 & 132987476 & 124397441 & 93.5 \\
\hline Hopelchén & 141502367 & 138410422 & 97.8 & 164956663 & 153495372 & 93.0 & 163440833 & 152900983 & 93.5 \\
\hline Palizada & 89634284 & 76308740 & 85.1 & 105543387 & 100259444 & 94.1 & 113619521 & 110343241 & 97.1 \\
\hline Tenabo & 71926120 & 66733607 & 92.8 & 80342795 & 78824165 & 98.1 & 90016084 & 85033994 & 94.5 \\
\hline Totales & 3335210159 & 2742074885 & 82.2 & 3782251436 & 3263087620 & 86.3 & 3 907787888 & 3307151845 & 84.6 \\
\hline
\end{tabular}

Fuente: elaboración propia con base en la legislación aportada e informes de gobiernos municipales. 